\title{
Sulfated Triterpene Derivatives from Fagonia
}

\section{arabica}

Angela Perrone,${ }^{\dagger}$ Milena Masullo,${ }^{\dagger}$ Carla Bassarello,${ }^{\dagger}$ Arafa I. Hamed,${ }^{\ddagger}$ Maria Antonietta Belisario ${ }^{\dagger}$ Cosimo Pizza,${ }^{\dagger}$ and Sonia Piacente ${ }^{*}$,

Dipartimento di Scienze Farmaceutiche, Università degli Studi di Salerno, Via Ponte Don Melillo, 84084 Fisciano, Salerno, Italy and Faculty of Science, South Valley University, Aswan 81528, Egypt

piacente@unisa.it

* Author to whom correspondence should be addressed. Tel.: ++39089969763. Fax: ++39089969602. E-mail piacente@ unisa.it

${ }^{\dagger}$ Università degli Studi di Salerno.

${ }^{\ddagger}$ Faculty of Science, South Valley University, Aswan. 


\section{Supporting Information}

\section{Biological Activity.}

Materials. All reagents are purchased from Sigma-Aldrich (St. Louis, MO, USA).

Cell Cultures. Human monocytic leukemia U937 cells were maintained in RPMI 1640 medium supplemented with $10 \%(\mathrm{v} / \mathrm{v})$ fetal bovine serum, $2 \mathrm{mM}$ L-glutamine and antibiotics $(100 \mathrm{U} / \mathrm{mL}$ penicillin, $100 \mu \mathrm{g} / \mathrm{mL}$ streptomycin) at $37^{\circ} \mathrm{C}$ in humidified atmosphere with $5 \% \mathrm{CO}_{2}$. To ensure logarithmic growth, cells were subcultured every two days. A stock solution of each compound (50 $\mathrm{mM}$ ) was prepared in DMSO and stored at $-20^{\circ} \mathrm{C}$. Just before using, an aliquot of the stock solution was diluted in sterile culture medium to the appropriate concentration. In all experiments, the final concentration of DMSO did not exceed $0.15 \%(\mathrm{v} / \mathrm{v})$.

Cell Proliferation and Viability. U937 cells were seeded in 96 well-plates at a cell density of $2 \mathrm{x}$

$10 \%$ well. After the addition of different concentrations of compounds 1-6, cells were allowed to grow for 24 and $48 \mathrm{~h}$. Control cells received the same amount of vehicle only. At the end of the incubation times the number of cells was quantified by using the tetrazolium salt-based assay, WST-1. ${ }^{1}$ To exclude any interference between test compounds and the WST-1 reagent, cell growth was randomly evaluated by the trypan blue exclusion method. In the range of tested concentrations, data obtained by cytometric counts well correlated with those obtained with the colorimetric assay.

\section{References and Notes}

(1) McCluskey, C.; Quinn, J. P.; McGrath, J. W. Microb. Ecol. 2005, 49, 379. 